\title{
Cardiac Electrophysiology Study
}

National Cancer Institute

\section{Source}

National Cancer Institute. Cardiac Electrophysiology Study. NCI Thesaurus. Code C80414.

A cardiac procedure performed under fluoroscopy to determine the area of the heart that is the source of aberrant electrical impulses that give rise to arrhythmias. Aberrant pathways can be terminated by ablation. 